\title{
Statistics of the earthquakes in the central Himalaya and its vicinity in last 56 years, with an emphasis in the 25 April 2015 Gorkha, Nepal earthquake
}

\author{
Ram Krishna TIWARI ${ }^{1,2, *}$ (D), Harihar PAUDYAL ${ }^{2}$ (]) \\ ${ }^{1}$ Central Department of Physics, Tribhuvan University, \\ Kirtipur, Kathmandu, Nepal \\ ${ }^{2}$ Birendra Multiple Campus, Tribhuvan University, \\ Bharatpur, Chitwan, Nepal
}

\begin{abstract}
To understand the variation of stress levels in the region $80^{\circ} \mathrm{E}-89^{\circ} \mathrm{E}$ and $26^{\circ} \mathrm{N}-31^{\circ} \mathrm{N}$, the statistical analysis of earthquake frequency-magnitude distribution and spatio-temporal variation of fractal correlation dimension of earthquake epicenter distribution are estimated. The analysis is carried out on declusterised catalogue containing 1185 events of 56 years from February 1964 to November 2020. The study area is divided into three regions the western Nepal and vicinity (Region A), central Nepal and vicinity (Region B) and eastern Nepal and vicinity (Region C), respectively. The magnitude of completeness $\left(M_{c}\right)$ varies from 3.6 to 4.0 for the study period. The spatial fractal dimension $\left(D_{c}\right)$ and $b$-value are calculated as $1.89 \pm 0.02$ and $0.68 \pm 0.03$ for the western Nepal, $1.76 \pm 0.01$ and $0.60 \pm 0.05$ for the central Nepal, whereas they are estimated as $1.85 \pm 0.02$ and $0.63 \pm 0.03$ for the eastern part of the Nepal. The $b$-values obtained for all three regions are very low comparing to global average value of 1 . The time clustering of the events in the respective regions are $0.26 \pm 0.003,0.31 \pm 0.004$ and $0.26 \pm 0.02$ as indicated by temporal fractal dimension $\left(D_{t}\right)$. The higher $D_{c}$, lower $b$ and $D_{t}$ values associated with the regions indicate high stress concentration and stronger epicenter clustering in these regions. The strongly increasing trend of fractal dimension and strongly decreasing trend of $b$-value show the high probabilities of occurring the large earthquake in both central Nepal $\left(82.5^{\circ} \mathrm{E}-85.5^{\circ} \mathrm{E}\right.$ and $\left.27.5^{\circ} \mathrm{N}-30^{\circ} \mathrm{N}\right)$ and eastern Nepal $\left(85.5^{\circ} \mathrm{E}-88.2^{\circ} \mathrm{E}\right.$ and $\left.26.45^{\circ} \mathrm{N}-28.6^{\circ} \mathrm{N}\right)$ as compared to western Nepal $\left(80^{\circ} \mathrm{E}-82.5^{\circ} \mathrm{E}\right.$ and $\left.28^{\circ} \mathrm{N}-30.5^{\circ} \mathrm{N}\right)$. This statistical analysis of spatial and temporal characteristics of the earthquake activity may give significant signs of the future seismic hazard along central Himalaya region.
\end{abstract}

Key words: magnitude of completeness, $b$-value, fractal dimension, clustering of earthquakes

\footnotetext{
*corresponding author, e-mail: ram.tiwari@bimc.tu.edu.np
} 


\section{Tectonics of the Himalaya}

The Himalaya, the youngest and the highest mountain range in the world is resulted from the collision of the Indian and Eurasian plates (Bilham, 2019; Wang and Fialko, 2015). After the collision, subsequent thrusting of Indian plate into the Eurasian plate led to the formation of the Himalaya range and the largest and highest plateau - Tibetan plateau (Butler et al., 200\%; DeCelles et al., 2014; Ni, 1989; Pandey et al., 1995). The mechanism of the formation of the Himalaya is that at some point between $65 \mathrm{Ma}$ (million years ago) and $45 \mathrm{Ma}$, India collided with Eurasia creating the Indus Yarlung Suture (IYS) - a zone that delineates the approximate boundary between the Indian and Eurasian plate. Thereafter the elevation of the Himalayan Mountain range began to take place in which the Eurasian plate was partly crumpled and buckled up above the Indian plate. Finally, the Himalayas gain their present height between 2.5 Ma and 1.8 Ma (Cattin et al., 2001; DeCelles et al., 2002; Molnar and Pandey, 1989; Webb et al., 2011). The dominant push of the Indian continental crust breaks itself into a lower and upper block at a depth. The breaking plane separating these two blocks of the Indian crust is called the Main Himalayan Thrust (MHT). It is gentle north dipping fault with $75 \mathrm{~km}$ width and three splays (DiPietro and Pogue, 2004). The Main Central Thrust (MCT) is the oldest, the Main Boundary Thrust (MBT) is the younger and the Main Frontal Thrust (MFT) or Himalaya Frontal Thrust (HFT) is southernmost and the youngest splay which is also the surface exposure of MHT. These structures strike the entire length of the Himalayan Arc (Shanker et al., 2011; Yin et al., 2010). The Main Central Thrust is a major intra-continental fault along $2200 \mathrm{~km}$ of the Himalaya Mountain belt where the Indian plate has pushed under the Eurasian plate along the Himalaya (DiPietro and Pogue, 2004). The MCT and South Tibetan Detachment (STD) run in sub-parallel way and bound a thick bundle of mid-crustal rocks that extend from the Himalayan front to the north beneath southern Tibet (Kellett et al., 2019). The MBT is another major thrust fault that runs parallel to the MFT with a spacing distance of about $20 \mathrm{~km}$. In addition, several lineaments like the Motihari Gaurishanker, Motihari Everest, Arun, Kanchenjunga etc. in eastern Nepal produce noticeable offsets on the MCT and MBT. Many others lineaments like Karnali, Judi, Thaple are establish faults as known from ground map- 
ping in the west of the Kathmandu fault (Dasgupta et al., 1987; Prakash et al., 2016; Upreti et al., 2007) (Fig. 1).

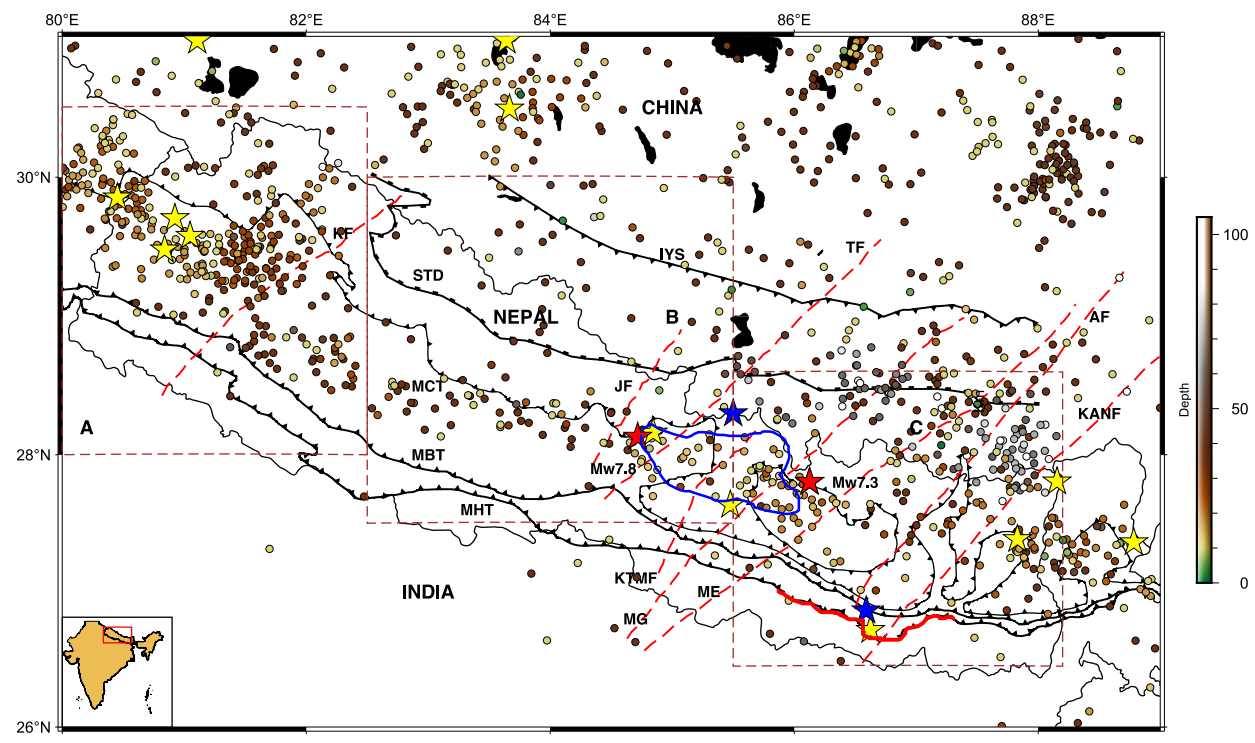

Fig. 1. Spatial distribution of 1185 earthquake events in the study region. 1170 earthquakes having magnitude $\leq 5.9 \mathrm{mb}$ are shown by solid circle. Color of the circle indicates the depth of the earthquake events. 13 yellow stars stand for the earthquake events $\geq 6 \mathrm{mb}$ and 2 red stars for Gorkha earthquake ( $\mathrm{Mw}$ 7.8) and Dolakha earthquake (Mw 7.3). Blue stars for 1833 Kathmandu earthquake (M 7.7) and 1934 Nepal-Bihar earthquake (M 8.3). Regions of interest are demarcated by orange box into regions A, B and C. Inset map at bottom left corner of the map shows study region bounded by red box. Major thrusts of the region MHT, MBT, MCT and STD are shown along with IYS. Regional faults are depicted by dashed lines where KF is Karnali fault, JF is Judi fault, TF is Thaple fault, KTMF is Kathmandu fault, MG is Motihari Gaurishanker fault, ME is Motihari Everest fault, AF is Arun fault and KANF is Kanchenjunga fault. The blue contour indicates the approximate position of rupture rim of mainshock of Gorkha earthquake (Grandin et al., 2015; Letort et al., 2016) and red wavy line over MHT indicates the rupture length ( $150 \mathrm{~km}$ in Nepal) of the 1934 Bihar-Nepal earthquake (Sapkota et al., 2013; Wei et al., 2018).

\section{History of earthquakes in Nepal}

The cause of a major geo-hazard in the Himalayas is/are earthquakes. The Main Himalayan Thrust (MHT) constantly gathers the massive amounts 
of strain and rupture process along it is the source of great earthquakes that have been documented along the range. (Bilham, 2019; Hubbard et al., 2016). Nepal measures about $880 \mathrm{~km}$ along its Himalayan axis by 150 to $250 \mathrm{~km}$ across so it is highly vulnerable to a disaster like earthquakes. In the earthquake history of Nepal two big earthquakes registered were 7.7 magnitude earthquake of 1833 that killed 414 people and 8.3 magnitude earthquake of 1934 that killed 8519 people (Joshi and Kaushik, 2017). The comparatively much smaller earthquakes that visited the nation were 1980 earthquake of 6.5 magnitude in western part of Nepal that killed 103 people, and 1988 earthquake of magnitude 6.5 in eastern part of Nepal that killed 721 people (Chhetri, 2018; Miyake et al., 2017). The most destructive earthquakes of 1934, 1980, 1988, and 2015 AD (Gorkha earthquake, 25 April) caused heavy fatalities and destruction of physical properties. The Gorkha event that ruptured a $50 \mathrm{~km}$ segment of the MHT has ended eastward in the area that was already broken during the 1934 Bihar-Nepal earthquake (Adhikari et al., 2015; Elliott et al., 2016; Ramesh et al., 2018). The earthquake is located at $15 \mathrm{~km}$ depth with epicenter at $28.147^{\circ} \mathrm{N}-84.708^{\circ} \mathrm{E}$. Among the intense aftershock sequences, two larger aftershocks of $\mathrm{Mw} 6.6$ and $\mathrm{Mw} 6.7$ were followed by the largest aftershock of magnitude $\mathrm{Mw} 7.3$ on the southeastern end of the main rupture (Avouac et al., 2015; Mitra et al., 2015).

It is believed that the Gorkha earthquake did not release all the stress as it was expected to release. It would take the really big earthquake of $\mathrm{Mw} 8$ and above for the strain to be relieved (Bilham, 2019; Sreejith et al., 2018). The partial rupture caused by the 1833 earthquake and the 2015 earthquake may initiate great earthquake in future by uncovering the shallow sealed slice of the MHT (Sreejith et al., 2018). They further recommended that some of this stress has shifted west to an area enlarging from Pokhara, Nepal to the Delhi, India (Bilham, 2019; Grandin et al., 2015). The central gap stretching from east Uttarakhand to central Nepal has been recognized that might fail, or collapse, either individually or in tandem with neighboring segments, in future earthquakes ( $\mathrm{Mw}$ 8.5-8.7) (Bilham, 2019). Even though, there is a long history of Himalayan research, the seismic activity and seismogenic structures of the Himalayan range is not fully understood yet. The study therefore attempts to understand the seismic activity as well as stress level in central Himalaya region in terms of $b$-value of frequency 
magnitude distribution and the spatio-temporal clustering of the earthquake events for the period of last 56 years.

\section{Frequency magnitude distribution and fractal geometry}

Earthquake epicenters/hypocenters can be considered as to be point events in space and time. If the occurrence of one earthquake is uncorrelated with other earthquakes events, then the distribution of events can be explained by Poisson (random) distribution having well-understood mathematics (Greenhough and Main, 2008; Wu et al., 2019). In regional seismicity studies, the distributions are not Poisson (Smalley et al., 1987; Knopoff, 2000) so cannot be explained by purely Poisson process. Then the distribution of events is explained by fractal geometry which applies scale invariant properties to study earthquakes. It is well known that earthquake phenomenon exhibit a scale-invariant character in several statistical features like Gutenberg-Richter (GR) earthquake sizes power law distribution (Gutenberg and Richter, 1944), fractal dimension of epicenters/hypocenters etc. The GR relationship is:

$\log N=a-b M$.

In the relation above, $N$ is the cumulative number of events having magnitude $\geq M$, the constant ' $a$ ' is the seismicity of the region, and ' $b$ ' is the $b$-value of the earthquake frequency magnitude distribution. The $b$-value for earthquakes distribution that covers large area and extended time is typically equal to 1 . The global study on $b$-value reveals that $b$-value varies significantly between individual fault zones, time, and space (Nuannin, 2006; Schorlemmer et al., 2005). Its variation is systematic in the period preceding a major earthquake (Smith, 1981). A high $b$-value means plenty of smaller events compared to larger ones and vice versa (Yeken, 2016). For the fractal behavior of earthquakes, fractal dimension is usually favored to investigate the clustering properties and size-scaling characteristics of earthquake parameters. Fractal distributions are the only distributions which do not include a typical length scale, and so, can be practicable to scale invariant phenomena (Shcherbakov et al., 2015, 2004). The temporal correlation dimension shows that earthquake occurrence is characterized by clustering properties with both short and long-time scales (Mondal and Roy, 2016; 
Nakaya and Hashimoto, 2002).

\section{Data and methodology}

Our study is limited to the region $80^{\circ} \mathrm{E}-89^{\circ} \mathrm{E}$ and $26^{\circ} \mathrm{N}-31^{\circ} \mathrm{N}$ which covers the total area of Nepal and its vicinity. Analysis is done on the database prepared from the catalogue of ISC (International Seismological Centre) and USGS (United State Geological Survey). The time window of study is from 1964-01-01 to 2020-11-23. We retrieved the 2457 earthquakes data from the above-mentioned sources. After declusterisation (Gardner and Knopoff, 1974), 1185 events are retained for the region where 15 events are with magnitude $\geq 6 \mathrm{mb}$ and 1170 events are less than $6 \mathrm{mb}$. The study region is further segmented into three regions containing 777 earthquake events altogether. The segmentation of the region is based on the nature of the faulting. The thrust dominated part appears in the western and central Nepal region, whereas, in the eastern Nepal, it is combination of thrust and strike-slip (Shanker et al., 2011). The regions segmented are:

(I) Western Nepal and its vicinity (Region A) $80^{\circ} \mathrm{E}-82.5^{\circ} \mathrm{E}$ and $28^{\circ} \mathrm{N}-$ $30.5^{\circ} \mathrm{N}$ comprising 351 events.

(II) Central Nepal and its vicinity (Region B) $82.5^{\circ} \mathrm{E}-85.5^{\circ} \mathrm{E}$ and $27.5^{\circ} \mathrm{N}-$ $30^{\circ} \mathrm{N}$ comprising 141 events.

(III) Eastern Nepal and its vicinity (Region C) $85.5^{\circ} \mathrm{E}-88.2^{\circ} \mathrm{E}$ and $26.45^{\circ} \mathrm{N}-$ $28.6^{\circ} \mathrm{N}$ comprising 285 events.

The magnitude of completeness is computed by the first derivative of the frequency magnitude curve (Wiemer and Wyss, 2000). The maximum likelihood estimation (MLE) method $(A k i, 1965)$ was used for the calculation of $b$-value. The error estimation of the $b$-value and $M_{c}$ is based on the bootstrapping method (Amorèse et al., 2010):

$b=\frac{\log _{10} \mathrm{e}}{M_{a}-(M-\Delta M / 2)}$,

where e is a constant, $M_{a}$ is the average magnitude, $M$ is the minimum magnitude in the catalogue and $\Delta M$ is the binning width of the catalogue $(A k i, 1965)$. An estimate of the standard deviation $(\delta b)$ of the $b$-value is given as suggested by (Shi and Bolt, 1982): 
$\delta b=2.3 b^{2} \sqrt{\frac{\sum_{i}^{N}\left(M_{i}-M_{a}\right)^{2}}{n_{s}\left(n_{s}-1\right)}}$,

where $n_{s}$ is the sample size (total number of events of the sample).

The Grassberger and Procaccia (1983) correlation dimension calculation method or sphere counting method is among the extensively used method to study space time characteristics of earthquake activity. It is based on power law and is used for spatio-temporal studies on the space-time characteristics of earthquake activity for various parts of the world (Oncel and Wilson, 200\%; Ormeni et al., 201\%; Pailoplee and Choowong, 2014; Roy et al., 2011). In this method the correlation integral function is defined as:

$C(r)=\frac{2}{N(N-1)} \sum_{\substack{i, j=1 \\ i \neq j}}^{N} H\left(r-\left|X_{i}-X_{j}\right|\right)$,

where $N$ is the total number of earthquakes in the given window, $X_{i}-X_{j}$ is the angular distance between two events, calculated by using spherical triangle method (Hirata, 1989), and $H\left(r-\left|X_{i}-X_{j}\right|\right)$ is the Heaviside step function where $r$ is the scaling radius.

The clue of possible approaching phase for large earthquakes can be better understood by investigating the temporal fluctuations of seismic sequences. It can be done by calculating the temporal correlation dimension based on the correlation integral function (Mondal and Roy, 2016; Nakaya and Hashimoto, 2002):

$C(\tau)=\frac{2}{N(N-1)} \sum_{\substack{i, j=1 \\ i \neq j}}^{N} H\left(\tau-\left|t_{i}-t_{j}\right|\right)$,

where $N$ is the number of total earthquakes in the given window, $\tau$ is scaling time, $t_{i}-t_{j}$ is the inter occurrence time and $H\left(\tau-\left|t_{i}-t\right|\right)$ is the Heaviside step function. Now the correlation dimension can be defined from the power law relations:

$C(r) \sim r^{D}, \quad$ for spatial correlation dimension and

$C(\tau) \sim \tau^{D}, \quad$ for temporal correlation dimension. 
The graphs are plotted for $\log r-\log C(r)$ and $\log \tau-\log C(\tau)$ then after respective fractal dimensions $(D)$ can be obtained as the slope of the linear segment of the graph. The time variation of $M_{c}$ and $b$-value are calculated by taking window size $=100$, minimum number of events $=50$, window overlap $=4 \%$, bootstraps $=200$, magnitude binning $=0.1$ from Zmap software.

\section{Results and discussion}

The magnitude of earthquakes versus time in the western Nepal and vicinity is shown in Fig. 2a which shows the largest earthquake of the region was $6.1 \mathrm{mb}$ on 1980 . The $b$-value for the region was computed to be very low $(0.68 \pm 0.03)$ comparing to the global average value of 1 for the period of the study (Table 1 and Fig. 2c). The $b$-value before Gorkha earthquake (from window 1 to window 8) ranges from $0.84 \pm 0.08$ to $0.79 \pm 0.08$ and it is slightly high after Gorkha earthquake $(0.90 \pm 0.09)$ and thereafter it is around 0.86 to 0.87 . The spatial correlation dimension $\left(D_{c}\right)$ varied from 1.52 to 1.94 for different windows while it was noticed $1.89 \pm 0.02$ for entire region (Table 1 and Fig. 2e). It was suggested the $D_{c}$ value of seismically active region ranges between 0 and 2 (Singh et al., 2009; Tosi, 1998). Thus, the western Nepal could be interpreted as being seismically active. Moreover, the spatial fractal dimension greater than 1.5 indicates the faults in the region are approaching to the near planar structure. The temporal correlation dimension $\left(D_{t}\right)$ varied between 0.22 to 0.31 for different windows and it was computed as $0.26 \pm 0.003$ for entire study period (Table 1 and Fig. 2f). The results indicate that the time clustering of earthquakes could be homogeneous (or monofractal).

The maximum $M_{c}$ above 5 is found at the beginning of the computations before 1980. Thereafter it is found decreasing and minimum $M_{c}$ value is computed for the catalogue after 2010 between 3.6 and 3.8. After 2015 it is around 3.8 (see Fig. 2b). The $M_{c}$ value for entire period of study is noticed to be 3.9 (Table 1 ). The temporal variation of $b$-value is constant around the global average value of 1 . The lowest value of 0.81 was observed for 11 May 2010. It was noticed 0.88 for 14 January 2014 and just around 1 after 2015 Gorkha earthquake (Fig. 2d). There are no distinct earthquake precursors before the 2015 Gorkha earthquake according to the temporal 
(a)



(c)

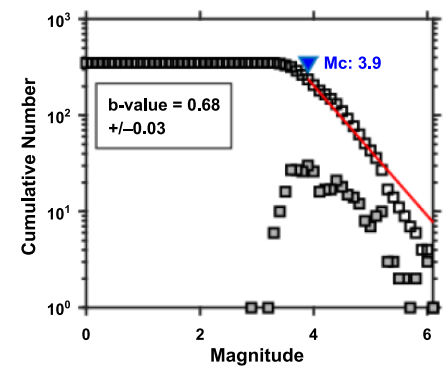

(e)

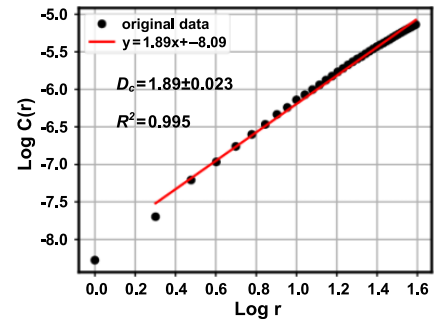

(b)

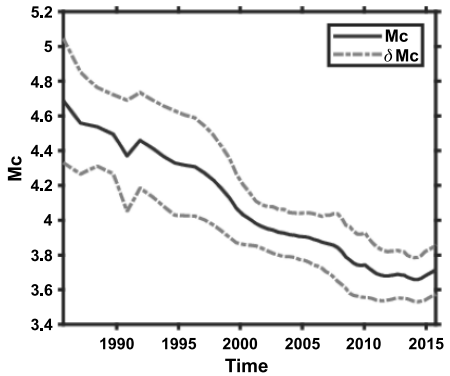

(d)

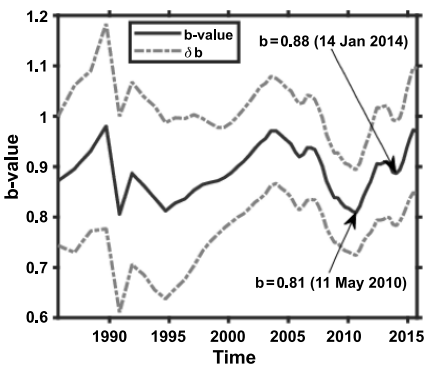

(f)

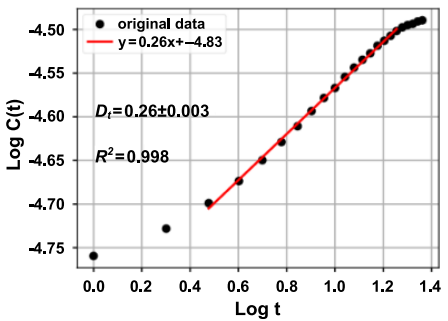

Fig. 2. Graphs showing (a) temporal variations of magnitude of the earthquake, (b) time variations of magnitude of completeness $M_{c}$ with standard deviation $\left(\delta M_{c}\right)$ shown by the dashed lines, (c) frequency magnitude distribution $b$-value (d) temporal variation of $b$-value with standard deviation $\left(\delta b_{c}\right)$, (e) spatial correlation dimension (f) temporal correlation dimension for earthquake events from 1964 to 2020 in the demarcated region A.

variations of $b$-value in western part of the Nepal.

The magnitude of earthquakes versus time in the central Nepal and vicinity is shown in Fig. 3a showing $6.9 \mathrm{mb} 2015$ Gorkha earthquake as the biggest event in the region so far. The $b$-value in this region was computed to be very low $(0.60 \pm 0.05)$ than the global average value of 1 during pe- 
Tiwari R. K., Paudyal H.: Statistics of the earthquakes in the central...

$(321-343)$

Table 1. Time window, $b$-value with completeness magnitude $M_{c}$, temporal correlation dimension $\left(D_{t}\right)$ and spatial correlation dimension $\left(D_{c}\right)$ with their coefficient of determination $\left(R^{2}\right)$ for 11 windows (10 windows each of 100 events and 11th window of 101 events) of region $\mathrm{A}$.

\begin{tabular}{|c|c|c|c|c|c|c|c|}
\hline Window & Time & $b$-value & $M_{c}$ & $D_{t}$ & $R^{2}$ & $D_{c}$ & $R^{2}$ \\
\hline 1 & $\begin{array}{l}1964-05-24- \\
1998-05-20\end{array}$ & $0.84 \pm 0.08$ & 4.5 & $0.22 \pm 0.004$ & 0.995 & $1.68 \pm 0.009$ & 0.999 \\
\hline 2 & $\begin{array}{l}1978-03-07- \\
2002-06-04\end{array}$ & $0.69 \pm 0.06$ & 4.1 & $0.24 \pm 0.003$ & 0.998 & $1.78 \pm 0.02$ & 0.994 \\
\hline 3 & $\begin{array}{l}1988-05-15- \\
2004-04-03\end{array}$ & $0.87 \pm 0.09$ & 4.1 & $0.26 \pm 0.003$ & 0.998 & $1.72 \pm 0.02$ & 0.995 \\
\hline 4 & $\begin{array}{l}1994-07-17- \\
2006-04-15\end{array}$ & $0.93 \pm 0.10$ & 3.9 & $0.31 \pm 0.004$ & 0.997 & $1.62 \pm 0.01$ & 0.999 \\
\hline 5 & $\begin{array}{l}1998-07-15- \\
2008-12-26\end{array}$ & $0.86 \pm 0.08$ & 3.8 & $0.29 \pm 0.003$ & 0.998 & $1.58 \pm 0.01$ & 0.996 \\
\hline 6 & $\begin{array}{l}2002-06-04- \\
2010-06-13\end{array}$ & $0.94 \pm 0.09$ & 3.8 & $0.23 \pm 0.003$ & 0.998 & $1.52 \pm 0.02$ & 0.991 \\
\hline 7 & $\begin{array}{l}2004-04-17- \\
2012-07-11\end{array}$ & $0.80 \pm 0.08$ & 3.6 & $0.22 \pm 0.002$ & 0.999 & $1.70 \pm 0.02$ & 0.992 \\
\hline 8 & $\begin{array}{l}2006-05-05- \\
2014-02-11\end{array}$ & $0.79 \pm 0.08$ & 3.6 & $0.26 \pm 0.004$ & 0.997 & $1.64 \pm 0.02$ & 0.991 \\
\hline 9 & $\begin{array}{l}2009-01-23- \\
2015-10-19\end{array}$ & $0.90 \pm 0.09$ & 3.6 & $0.27 \pm 0.003$ & 0.998 & $1.94 \pm 0.03$ & 0.991 \\
\hline 10 & $\begin{array}{l}2010-06-13- \\
2017-07-15\end{array}$ & $0.87 \pm 0.09$ & 3.6 & $0.26 \pm 0.004$ & 0.996 & $1.93 \pm 0.03$ & 0.991 \\
\hline $\begin{array}{l}2012-07-28- \\
\text { Entire }\end{array}$ & $\begin{array}{l}1964-05-24- \\
2020-10-28\end{array}$ & $0.68 \pm 0.03$ & 3.9 & $0.26 \pm 0.003$ & 0.997 & $1.89 \pm 0.02$ & 0.995 \\
\hline
\end{tabular}

riod of the study (Table 2 and Fig. 3c). The $b$-value decreases from 0.71 to the lowest value of 0.68 and then increases up to 0.82 for the period of study. The low $b$-values $0.71 \pm 0.08$ and $0.68 \pm 0.07$ are observed for the window 2 (1979-01-01 to 2015-4-25) and window 3 (1985-10-21 to 2015-07-01). The slight decrease in $b$-value before Gorkha earthquake may be because of occurrence of foreshocks and variations in $b$-value after the earthquake is attributed to the aftershock activity [46]. The calculated spatial correlation dimension $\left(D_{c}\right)$ varied from 1.62 to 1.84 for different windows while it was 
(a)

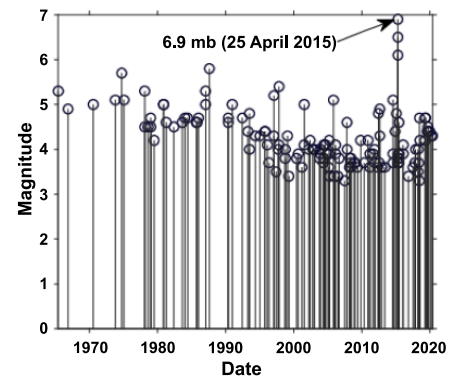

(c)



(e)

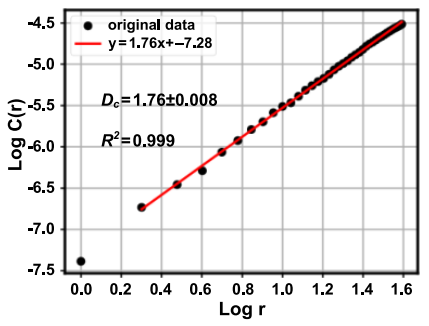

(b)

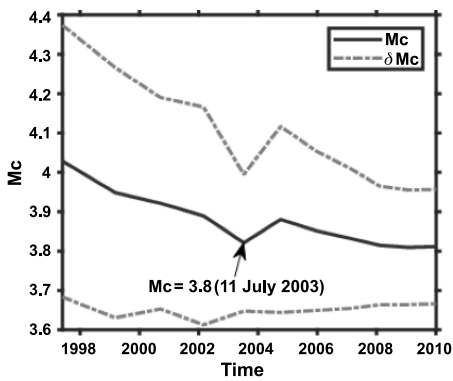

(d)

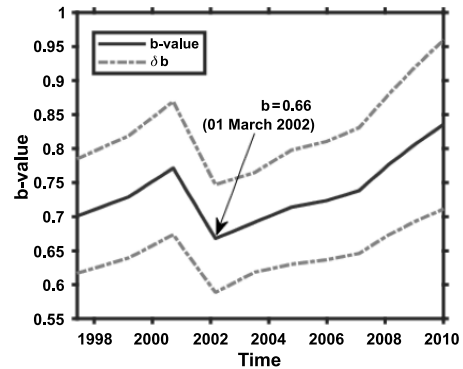

(f)

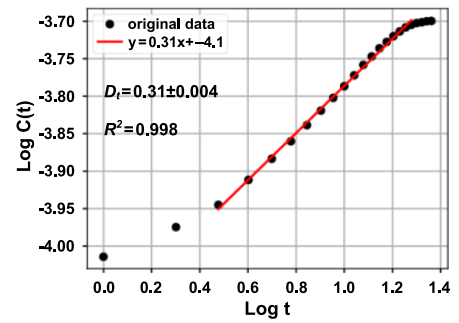

Fig. 3. Graphs showing (a) temporal variations of magnitude, (b) time variations of magnitude of completeness $\mathrm{M}_{c}$ with standard deviation $\left(\delta M_{c}\right)$ shown by the dashed lines, (c) frequency magnitude distribution $b$-value, (d) temporal variation of $b$-value with standard deviation $\left(\delta b_{c}\right)$, (e) spatial correlation dimension, (f) temporal correlation dimension for earthquake events from 1965 to 2020 in the demarcated region B.

noticed $1.76 \pm 0.01$ for entire study period (Table 2 and Fig. 3e). These results indicate that the central Nepal is seismically active with seismogenic structure of planar geometry. The temporal spatial correlation dimension $\left(D_{t}\right)$ varied between 0.27 to 0.30 for different windows and it was computed as $0.31 \pm 0.004$ for entire study period (Table 2 and Fig. 3f). The results 
Table 2. Time window, $b$-value with completeness magnitude $M_{c}$, temporal correlation dimension $\left(D_{t}\right)$ and spatial correlation dimension $\left(D_{c}\right)$ with their coefficient of determination $\left(R^{2}\right)$ for 5 windows (4 windows each of 100 events and 5 th window of 101 events) of region $\mathrm{B}$.

\begin{tabular}{|c|c|c|c|c|c|c|c|}
\hline Window & Time & $b$-value & $M_{c}$ & $D_{t}$ & $R^{2}$ & $D_{c}$ & $R^{2}$ \\
\hline 1 & $\begin{array}{l}1965-06-01- \\
2012-08-23\end{array}$ & $0.71 \pm 0.07$ & 4.0 & $0.27 \pm 0.002$ & 0.999 & $1.78 \pm 0.01$ & 0.996 \\
\hline 2 & $\begin{array}{l}1979-01-01- \\
2015-04-25\end{array}$ & $0.71 \pm 0.08$ & 4.0 & $0.29 \pm 0.004$ & 0.998 & $1.84 \pm 0.02$ & 0.996 \\
\hline 3 & $\begin{array}{l}1985-10-21- \\
2015-07-01\end{array}$ & $0.68 \pm 0.07$ & 3.7 & $0.29 \pm 0.003$ & 0.998 & $1.75 \pm 0.01$ & 0.997 \\
\hline 4 & $\begin{array}{l}1993-07-05- \\
2018-06-14\end{array}$ & $0.82 \pm 0.10$ & 3.7 & $0.30 \pm 0.005$ & 0.996 & $1.71 \pm 0.01$ & 0.998 \\
\hline 5 & $\begin{array}{l}1997-05-28- \\
2020-05-30\end{array}$ & $0.79 \pm 0.10$ & 3.7 & $0.29 \pm 0.004$ & 0.997 & $1.62 \pm 0.01$ & 0.999 \\
\hline $\begin{array}{l}\text { Entire } \\
\text { region B }\end{array}$ & $\begin{array}{l}1965-06-01- \\
2020-05-30\end{array}$ & $0.60 \pm 0.05$ & 3.7 & $0.31 \pm 0.004$ & 0.998 & $1.76 \pm 0.01$ & 0.996 \\
\hline
\end{tabular}

indicate that the time clustering of earthquakes can be considered to be homogeneous (or monofractal) for this region as well.

The maximum $M_{c}$ above 4.6 , is found at the beginning of the computations before 1990. Thereafter it is found decreasing in linear trend. The minimum $M_{c}$ value below 3.8 is computed for the catalogue around 2015 (Fig. $3 \mathrm{~b}$ ). The $M_{c}$ value for entire period of study noticed to be 3.7 (Table 2 ). The temporal variations show $b$-value very lower than 1 . The lowest value 0.66 is noted for 1 March 2002. Thereafter it seems rising gradually and it is just above 0.8 after 2010 (Fig. 3d).

The magnitude of earthquakes versus time in the eastern Nepal and vicinity is shown in Fig. 4a showing $6.7 \mathrm{mb}$ earthquake on 12 May 2015 as the biggest one. The $b$-value in this region was computed to be very low $(0.63 \pm 0.03)$ than the global average value of 1 for the period of the study (Table 3 and Fig. 4c). The $b$-values before Gorkha earthquake (from window 1 to window 5) range from $1.12 \pm 0.16$ to $0.86 \pm 0.10$ and after Gorkha earthquake it ranges from $0.82 \pm 0.11$ to $0.70 \pm 0.09$ (from window 6 to window 9 ). The results show increase in $b$-value for several years before earthquake and followed by a decrease after the occurrence of the Gorkha earthquake. This may be the indication of smaller events before the major events. The 
(a)

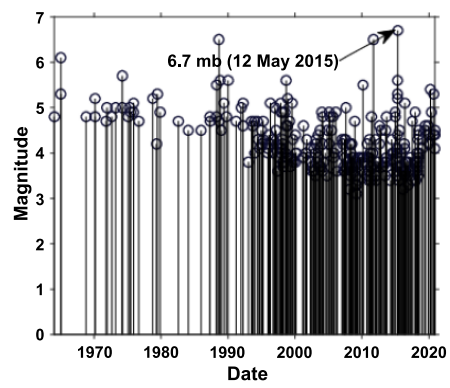

(c)

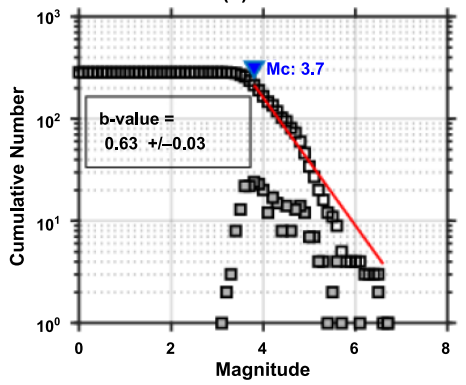

(e)

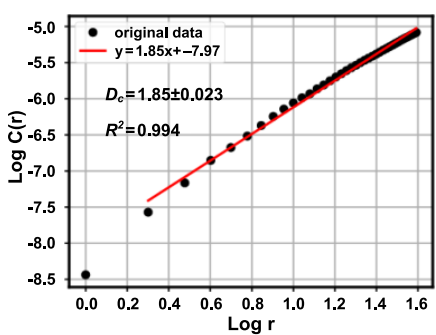

(b)



(d)

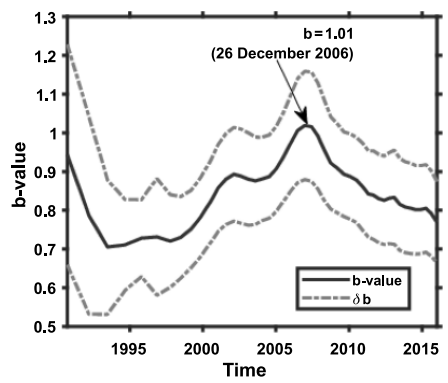

(f)

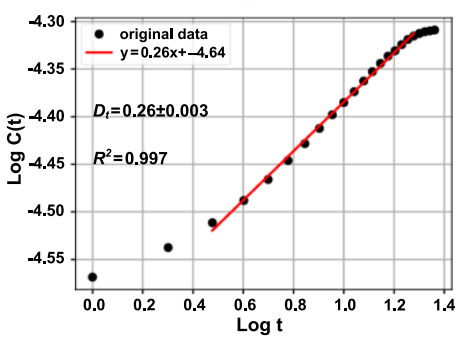

Fig. 4. Graphs showing (a) temporal variations of magnitude, (b) time variations of magnitude of completeness $M_{c}$ with standard deviation $\left(\delta M_{c}\right)$ shown by the dashed lines, (c) frequency magnitude distribution $b$-value, (d) temporal variation of $b$-value with standard deviation $\left(\delta b_{c}\right)$, (e) spatial correlation dimension, (f) temporal correlation dimension for earthquake events from 1964 to 2020 in the demarcated region C.

calculated spatial correlation dimension $\left(D_{c}\right)$ varied from 1.65 to 1.87 for different windows while it was noticed $1.82 \pm 0.002$ for entire study period (Table 3 and Fig. 4e). The $D_{c}$ value of seismically active region ranges between 0 and 2 (Tosi, 1998; Xu, 2011), thus, the eastern Nepal could be interpreted as being seismically active. The temporal spatial correlation 
Tiwari R. K., Paudyal H.: Statistics of the earthquakes in the central...

$(321-343)$

Table 3. Time window, $b$-value with completeness magnitude $M_{c}$, temporal correlation dimension $\left(D_{t}\right)$ and spatial correlation dimension $\left(D_{c}\right)$ with their coefficient of determination $\left(R^{2}\right)$ for 9 windows ( 8 window each of 100 events and 9 th window of 85 events) of region $\mathrm{C}$.

\begin{tabular}{|c|c|c|c|c|c|c|c|}
\hline Window & Time & $b$-value & $M_{c}$ & $D_{t}$ & $R^{2}$ & $D_{c}$ & $R^{2}$ \\
\hline 1 & $\begin{array}{l}1964-02-01- \\
2002-05-02\end{array}$ & $1.12 \pm 0.16$ & 4.7 & $0.26 \pm 0.004$ & 0.996 & $1.80 \pm 0.02$ & 0.996 \\
\hline 2 & $\begin{array}{l}1987-04-23- \\
2005-02-08\end{array}$ & $0.71 \pm 0.16$ & 4.0 & $0.22 \pm 0.003$ & 0.998 & $1.80 \pm 0.02$ & 0.995 \\
\hline 3 & $\begin{array}{l}1995-02-18- \\
2008-04-01\end{array}$ & $1.02 \pm 0.12$ & 4.2 & $0.29 \pm 0.003$ & 0.998 & $1.83 \pm 0.02$ & 0.995 \\
\hline 4 & $\begin{array}{l}1998-06-27- \\
2010-09-28\end{array}$ & $0.93 \pm 0.11$ & 3.9 & $0.28 \pm 0.004$ & 0.997 & $1.66 \pm 0.01$ & 0.999 \\
\hline 5 & $\begin{array}{l}2002-05-03- \\
2013-02-04\end{array}$ & $0.86 \pm 0.10$ & 3.7 & $0.25 \pm 0.003$ & 0.998 & $1.65 \pm 0.01$ & 0.998 \\
\hline 6 & $\begin{array}{l}2005-02-08- \\
2015-04-27\end{array}$ & $0.82 \pm 0.11$ & 3.9 & $0.25 \pm 0.004$ & 0.996 & $1.82 \pm 0.03$ & 0.996 \\
\hline 7 & $\begin{array}{l}2008-04-12- \\
2017-01-12\end{array}$ & $0.80 \pm 0.11$ & 3.7 & $0.28 \pm 0.005$ & 0.995 & $1.84 \pm 0.02$ & 0.997 \\
\hline 8 & $\begin{array}{l}2010-10-05- \\
2019-06-17\end{array}$ & $0.76 \pm 0.11$ & 3.8 & $0.28 \pm 0.004$ & 0.996 & $1.87 \pm 0.02$ & 0.997 \\
\hline 9 & $\begin{array}{l}2013-02-05- \\
2020-11-23\end{array}$ & $0.70 \pm 0.09$ & 3.8 & $0.26 \pm 0.003$ & 0.998 & $1.87 \pm 0.02$ & 0.997 \\
\hline $\begin{array}{c}\text { Entire } \\
\text { region C }\end{array}$ & $\begin{array}{l}1964-02-01- \\
2020-11-23\end{array}$ & $0.63 \pm 0.03$ & 3.8 & $0.26 \pm 0.003$ & 0.997 & $1.85 \pm 0.02$ & 0.994 \\
\hline
\end{tabular}

dimension $\left(D_{t}\right)$ varied between 0.22 to 0.29 for different windows and it was computed as $0.26 \pm 0.003$ for entire study period (Table 3 and Fig. 4f). The results indicate that the time clustering of earthquakes can be considered to be near homogeneous monofractal) for eastern Nepal also.

The maximum $M_{c}$ between 4.5 and 5 , is found at the beginning of the computations before 1985. Thereafter it is found decreasing in linear trend. The minimum $M_{c}$ value around 3.8 is computed for the catalogue after 2015 (Fig. 4b). The $M_{c}$ value for entire period of study noticed to be 3.8 (Table 3$)$. The temporal variation of $b$-value shows the highest $b$-value 1.01 for 26 December 2006 and $\sim 0.8$ before Gorkha earthquake (Fig. 4d).

The negative and weak correlation between $b$-value and spatial fractal dimension has been observed for all three regions (Fig. 5). The negative 

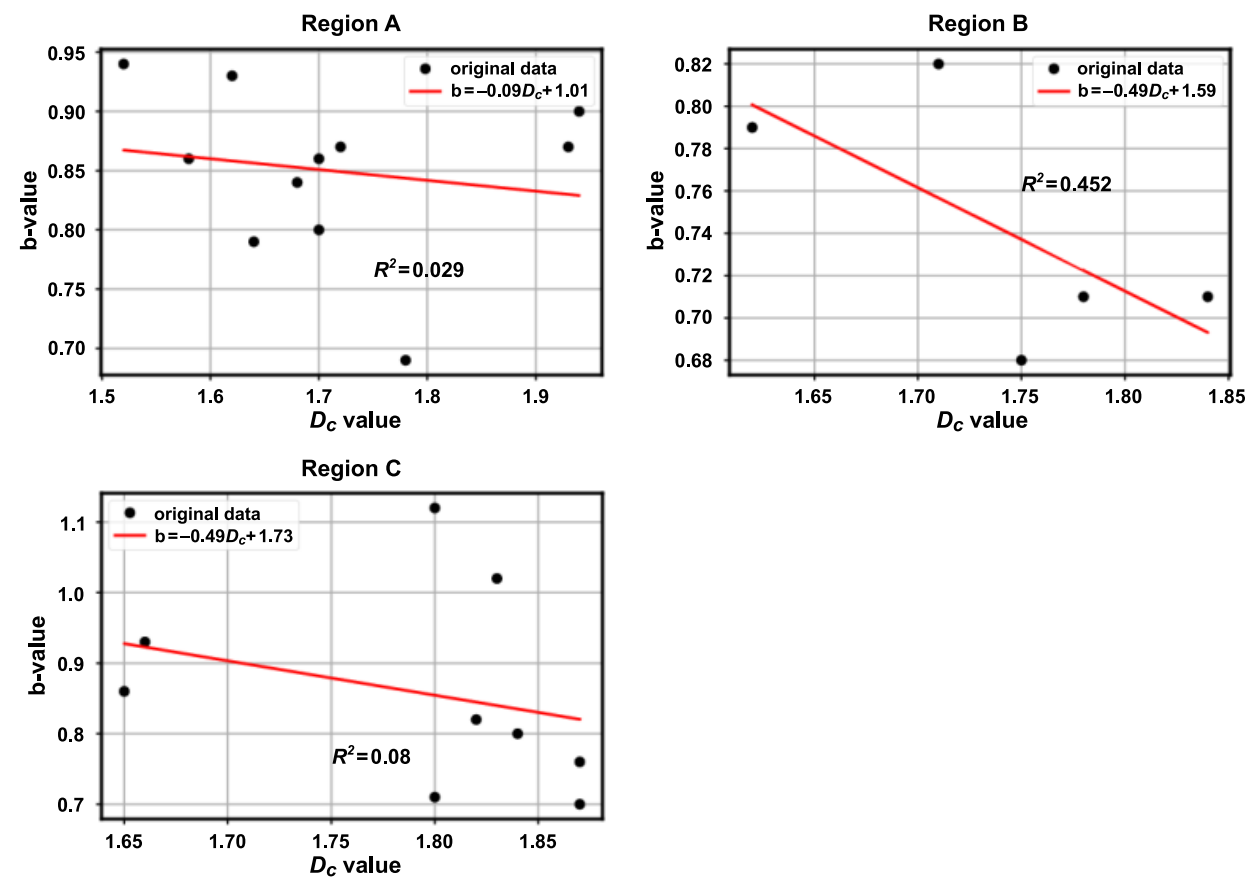

Fig. 5. Correlation between $b$-value and spatial correlation fractal dimension $\left(D_{c}\right)$ for regions $\mathrm{A}, \mathrm{B}$ and $\mathrm{C}$, respectively.

correlation indicates the release of the stress along the faults of a larger surface so there is a substantial likelihood of occurrence of huge magnitude earthquakes in the regions. The distribution of epicenters on larger surface area could also be understood by high spatial correlation dimension value computed for the regions (Table 1, Table 2, and Table 3). The negative correlation is also obtained from the findings of previous articles (Ghosh, 2020; Minocha and Parvez, 2020) for central Himalaya region. The findings (Minocha and Parvez, 2020) show no significant relation between $b$-value and the correlation dimension as indicated by correlation coefficient 0.26 .

The $b$-values obtained for all three regions acceptable for the region where dominant nature of the fault is thrust type. Schorlemmer et al. (2005) also indicated that the $b$-values of thrust mechanisms are low which also supports our study. Our results can also be compared numerically with the results of earlier researchers for the Himalayan region. For example, the 


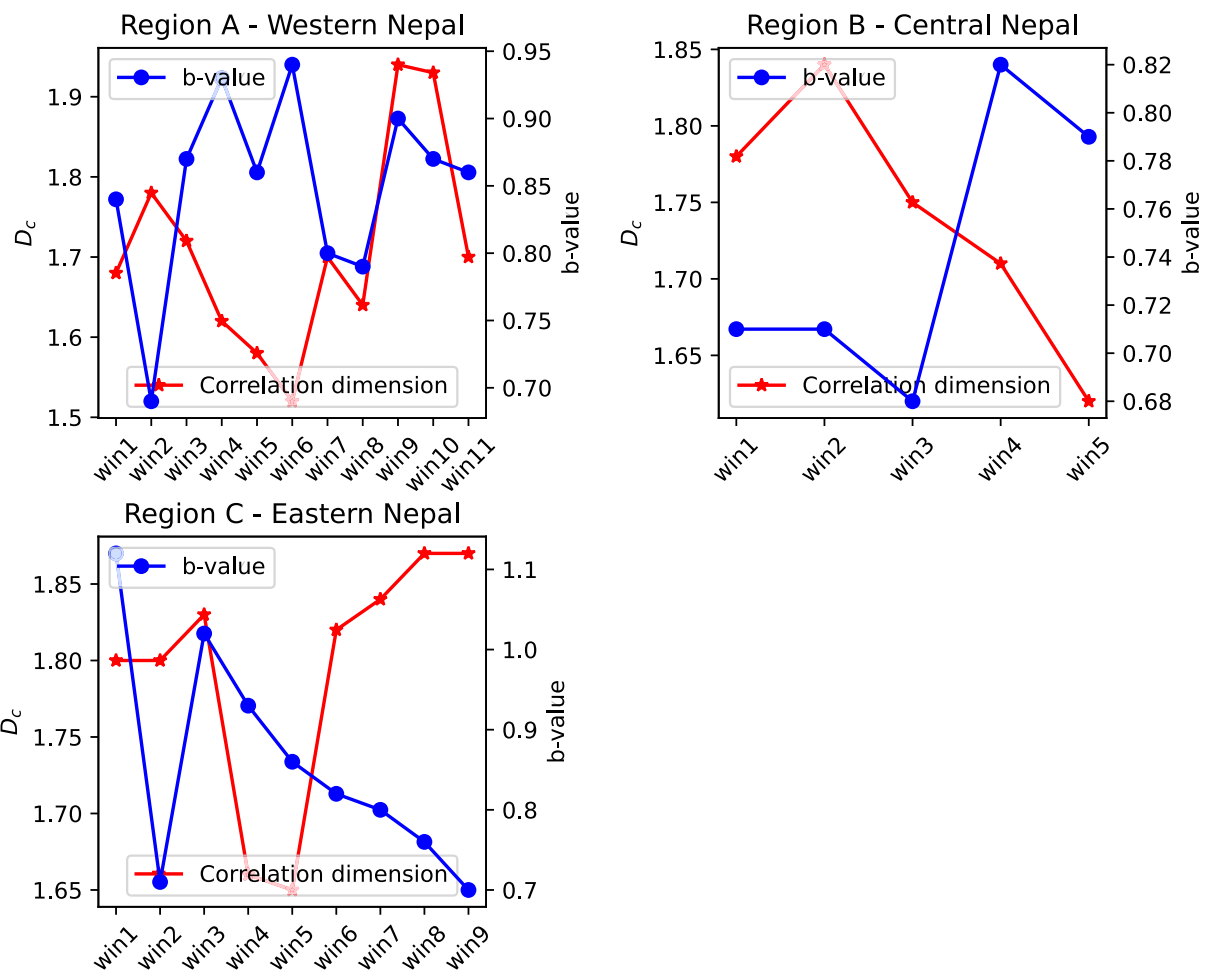

Fig. 6. Variations of the exponent $b$-value and $D_{c}$ for different time window for Western Nepal (Region A), Central Nepal (Region B), and Eastern Nepal (Region C) during the study period.

$b$-values were computed between 0.85 to 0.86 for central Himalaya region before the Gorkha earthquake (Ramesh et al., 2018). The two low $b$-value patches $(b<0.75)$, towards east and west of the 2015 Gorkha earthquake epicenter had revealed in the preceding works (Sreejith et al., 2018). In the study carried out by Tiwari and Paudyal (2021) the b-value was noted as $0.78 \pm 0.08$ for aftershocks sequences after Dolakha earthquake. The fractal dimension computed from this study can also be compared with the preceding works (Ghosh, 2020; Valerio et al., 2017). Valerio et al. (2017) computed fractal dimension ranging from 1.5 to 1.57 with average value of $R^{2}=0.96$ for the Gorkha earthquake sequences that lasted for about 130 day (about 4 and a half months). The work (Ghosh, 2020) computed the fractal dimension $\sim 2$ near the source region of Gorkha earthquake. Higher 
$D_{c}$ value and low $b$-value computed for all three regions indicate the release of stress is on the smaller fault plane that will increase the complexity in the nearby fault system (Nampally et al., 2018; Roy and Mondal, 2009).

Temporal changes in $b$-value and $D_{c}$ for different fixed events time window (Table 1, Table 2, and Table 3) are plotted in Fig. 6. These variations depict the possible temporal changes during the time 1964 and 2020. For Central Nepal (see Fig. 6) $D_{c}$ values show a strong increasing tendency and $b$-values show a strong decreasing tendency from 1979-01-01 to 2015-04-25 (Table 2, Window 2) before the devastating Gorkha earthquake. Similar trend i.e., increasing value of $D_{c}$ from 1.66 to 1.87 and decreasing $b$-value from 0.93 to 0.70 (Table 3 and Fig. 6) is noticed for eastern Nepal from 1998 onwards. This may suggest the adjacent large earthquake in the region. Since the higher value of the fractal dimension is more sensitive to heterogeneity in the magnitude distribution, it can be concluded that seismicity is more clustered at larger scales within smaller areas in the eastern Nepal. For western Nepal, no clear increasing or decreasing trend of both $b$-value and $D_{c}$ value is observed.

In the bulk of the study area, $M_{c}$ ranges from 3.6 to 4.0 and decrease of $M_{c}$ with time is noted which might be related to the improvement of seismic networks in the region. Chingtham et al. (2016) estimated the threedimensional distribution of $M_{c}$ and showed that Himalayan regions have higher $M_{c}$ as compared to Gangetic plain. The previous work (Yadav et al., 2012) have estimated the $M_{c}$ for northwest Himalaya and adjacent region considering $\mathrm{Mw} \geq 4.0$ and the results showed that $M_{c}$ varies from 4.3 to 4.7 which agrees the present study.

\section{Conclusion}

In this study, the completeness magnitude $M_{c}, b$-value of frequency magnitude distribution and fractal correlation dimension of earthquake's epicenter in Nepal and its vicinity were estimated by analyzing the homogeneous catalogue of 1185 events (1964-01-01 to 2020-11-23). The analysis is based on fixed event sliding window technique. $M_{c}$ value for the different time windows varies between 3.6 and 4.7 with dominating value $\leq 4.0$. For the most part of the study area, the value of $b$ is observed $\leq 0.94$, it suggests high stress in the crust that could increase as the result of the constant move- 
ment of Indian plate towards Eurasian plate. Consequently, the probability of occurrence of future large earthquakes in this area of Himalaya increases. $D_{c}$ value shows strong increasing trend and $b$-value shows strong decreasing trend before Gorkha earthquake in central Nepal region and similar trend is also noticed for eastern Nepal region. This could be the indication of impending large earthquake in the Eastern Nepal. For western Nepal, this study does not notice any pattern in the variation of these parameters. From temporal correlation dimension obtained for these three regions, it can be concluded that the time clustering of earthquake events is homogenous. This study enhances the knowledge of understanding the level of tectonic stress and the degree of heterogeneity of the earthquake sources in the central Himalayan region.

Acknowledgements. Author (RKT) would like to express acknowledgement to Tribhuvan University, Nepal for providing study leave and University Grants Commission (UGC), Nepal for providing monetary support for the PhD study. The authors would also like to thank the reviewers and editors for their suggestions and comments to improve the quality of this manuscript.

Software resources. The plotting software are Python, Generic Mapping Tools (Wessel et al., 2013) and ZMAP (Wiemer, 2001).

\section{References}

Adhikari L. B., Gautam U. P., Koirala B. P., Bhattarai M., Kandel T., Gupta R. M., Timsina C., Maharjan N., Maharjan K., Dahal T., Hoste-Colomer R., Cano Y., Dandine M., Guilhem A., Merrer S., Roudil P., Bollinger L., 2015: The aftershock sequence of the 2015 april 25 Gorkha-Nepal earthquake. Geophys. J. Int., 203, 3, 2119-2124, doi: 10.1093/gji/ggv412.

Aki K., 1965: Maximum likelihood estimate of $b$ in the formula $\log N=a-b M$ and its confidence limits. Bull. Earthq. Res. Inst. Univ. Tokyo, 43, 2, 237-239, doi: 10.150 83/0000033631.

Amorèse D., Grasso J.-R., Rydelek P. A., 2010: On varying b-values with depth: Results from computer-intensive tests for Southern California. Geophys. J. Int., 180, 1, 347-360, doi: 10.1111/j.1365-246X.2009.04414.x.

Avouac J.-P., Meng L., Wei S., Wang T., Ampuero J.-P., 2015: Lower edge of locked Main Himalayan Thrust unzipped by the 2015 Gorkha earthquake. Nat. Geosci., 8, 708-711, doi: $10.1038 /$ ngeo2518.

Bilham R., 2019: Himalayan earthquakes: A review of historical seismicity and early 21st century slip potential. In: Treloar P. J., Searle M. P. (Eds.): Himalayan Tectonics: A Modern Synthesis. Geol. Soc. Spec. Publ., 483, 423-482, doi : 10.1144/SP483.16. 
Butler R. W. H., Graham R. H., Ries A. C., 2007: Introduction: The deformation of continental crust and Mike Coward's impact on its understanding. In: Ries A. C., Butler R. W. H., Graham R. H. (Eds.): Deformation of the Continental Crust: The Legacy of Mike Coward. Geol. Soc. Spec. Publ., 272, 1-8, doi: 10.1144/GSL.SP. 2007.272. 01.01 .

Cattin R., Martelet G., Henry P., Avouac J.-P., Diament M., Shakya T. R., 2001: Gravity anomalies, crustal structure and thermo-mechanical support of the Himalaya of Central Nepal. Geophys. J. Int., 147, 2, 381-392, doi : 10.1046/j.0956-540X.2001.01 $541 . x$.

Chhetri M. B. P., 2018: Aftermath of Gorkha-Nepal Earthquake 2015: Lessons Learnt. Oceanogr. Fish. Open Access J., 8, 2, 555735, doi: 10.19080/ofoaj.2018.08.555 735.

Chingtham P., Sharma B., Chopra S., SinghaRoy P., 2016: Statistical analysis of aftershock sequences related with two major Nepal earthquakes: April 25, 2015, MW 7.8, and May 12, 2015, MW 7.2. Ann. Geophys., 59,5, S0540, doi: 10.4401/ag-7025.

Dasgupta S., Mukhopadhyay M., Nandy D. R., 1987: Active transverse features in the central portion of the Himalaya. Tectonophysics, 136, 3-4, 255-264, doi: 10.1016/00 40-1951 (87) 90028-X.

DeCelles P. G., Kapp P., Gehrels G. E., Ding L., 2014: Paleocene-Eocene foreland basin evolution in the Himalaya of southern Tibet and Nepal: Implications for the age of initial India-Asia collision. Tectonics, 33, 5 ,824-849, doi: 10.1002/2014TC003522.

DeCelles P. G., Robinson D. M., Zandt G., 2002: Implications of shortening in the Himalayan fold-thrust belt for uplift of the Tibetan Plateau. Tectonics, 21, 6, 12-112-25, doi : 10.1029/2001TC001322.

DiPietro J. A., Pogue K. R., 2004: Tectonostratigraphic subdivisions of the Himalaya: A view from the west. Tectonics, 23, 5, doi: 10.1029/2003TC001554.

Elliott J. R., Jolivet R., González P. J., Avouac J.-P., Hollingsworth J., Searle M. P., Stevens V. L., 2016: Himalayan megathrust geometry and relation to topography revealed by the Gorkha earthquake. Nat. Geosci., 9, 174-180, doi : 10.1038/ngeo2623.

Gardner J. K., Knopoff L., 1974: Is the sequence of earthquakes in Southern California, with aftershocks removed, Poissonian? Bull. Seismol. Soc. Am., 64, 5, 1363-1367, doi: $10.1785 /$ BSSA0640051363.

Ghosh U., 2020: Seismic Characteristics and Seismic Hazard Assessment: Source Region of the 2015 Nepal Earthquake Mw 7.8 in Central Himalaya. Pure Appl. Geophys., 177, 1, 181-194, doi : 10.1007/s00024-019-02318-w.

Grandin R., Vallée M., Satriano C., Lacassin R., Klinger Y., Simoes M., Bollinger L., 2015: Rupture process of the $M w=7.92015$ Gorkha earthquake (Nepal): Insights into Himalayan megathrust segmentation. Geophys. Res. Lett., 42, 20, 8373-8382, doi: 10.1002/2015GL066044.

Grassberger P., Procaccia I., 1983: Characterization of strange attractors. Phys. Rev. Lett., 50, 5, 346-349, doi: 10.1103/PhysRevLett.50.346.

Greenhough J., Main I. G., 2008: A poisson model for earthquake frequency uncertainties in seismic hazard analysis. Geophys. Res. Lett., 35, 19, L19313, 8-11, doi: 10.1029/2008GL035353. 
Gutenberg B., Richter C. F., 1944: Frequency of earthquakes in California. Bull. Seismol. Soc. Am., 34, 4, 185-188, doi: 10.1785/BSSA0340040185.

Hirata T., 1989: A correlation between the $b$ value and the fractal dimension of earthquakes. J. Geophys. Res., 94, B6,7507-7514, doi: 10.1029/JB094iB06p07507.

Hubbard J., Almeida R., Foster A., Sapkota S. N., Bürgi P., Tapponnier P., 2016: Structural segmentation controlled the 2015 MW 7.8 Gorkha earthquake rupture in Nepal. Geology, 44, 8, 639-642, doi : 10.1130/G38077.1.

Joshi V. M., Kaushik H. B., 2017: Historic earthquake-resilient structures in Nepal and other Himalayan regions and their seismic restoration. Earthq. Spectra, 33, 1_suppl, 299-319, doi: 10.1193/121616eqs240m.

Kellett D. A., Cottle J. M., Larson K. P., 2019: The South Tibetan Detachment System: History, advances, definition and future directions. Geol. Soc. Spec. Publ., 483, 1, 377-400, doi: 10.1144/SP483.2.

Knopoff L., 2000: The magnitude distribution of declustered earthquakes in Southern California. Proc. Natl. Acad. Sci. U.S.A., 97, 22, 11880-11884, doi : 10.1073/pnas. 190241297.

Letort J., Bollinger L., Lyon-Caen H., Guilhem A., Cano Y., Baillard C., Adhikari L. B., 2016: Teleseismic depth estimation of the 2015 Gorkha-Nepal aftershocks. Geophys. J. Int., 207, 3, 1584-1595, doi: 10.1093/gji/ggw364.

Minocha S., Parvez I. A., 2020: Self-organized fractal seismicity and b-value of aftershocks of the 2015 Gorkha earthquake, Nepal. Int. J. Geosci., 11, 8, 562-579, doi: 10.4236/ijg. 2020.118030.

Mitra S., Paul H., Kumar A., Singh S. K., Dey S., Powali D., 2015: The 25 April 2015 Nepal earthquake and its aftershocks. Curr. Sci., 108, 10, 1938-1943, doi: 10.18520 /cs/v108/i10/1938-1943.

Miyake H., Sapkota S. N., Upreti B. N., Bollinger L., Kobayashi T., Takenaka H., 2017: Special issue "the 2015 Gorkha, Nepal, earthquake and Himalayan studies: First results". Earth Planets Space, 69, 12, 2015-2016, doi : 10.1186/s40623-016-0597-8.

Molnar P., Pandey M. R., 1989: Rupture zones of great earthquakes in the Himalayan region. Proc. Indian Acad. Sci. - Earth Planet. Sci., 98, 1, 61-70, doi: 10.1007/BF 02880376.

Mondal S. K., Roy P. N. S., 2016: Temporal multifractal pattern of seismicity in northwest Himalayan region. J. Geol. Soc. India, 88, 5, 569-575, doi : 10.1007/s12594-016-05 22-6.

Nakaya S., Hashimoto T., 2002: Temporal variation of multifractal properties of seismicity in the region affected by the mainshock of the October 6, 2000 Western Tottori Prefecture, Japan, earthquake $(M=7.3)$. Geophys. Res. Lett., 29, 10, 133-1-1334, doi : 10.1029/2001g1014216.

Nampally S., Padhy S., Dimri V. P., 2018: Characterizing spatial heterogeneity based on the $b$-value and fractal analyses of the 2015 Nepal earthquake sequence. Tectonophysics, 722, 154-162, doi: 10.1016/j.tecto.2017.11.004.

Ni J. F., 1989: Active tectonics of the Himalaya. Proc. Indian Acad. Sci. - Earth Planet. Sci., 98, 71-89, doi: 10.1007/BF02880377. 
Nuannin P., 2006: The Potential of b-value Variations as Earthquake Precursors for Small and Large Events. PhD thesis, Uppsala University, SE-75236, Uppsala, Sweden.

Oncel A. O., Wilson T., 2007: Anomalous seismicity preceding the 1999 Izmit event, NW Turkey. Geophys. J. Int., 169, 1, 259-270, doi: 10.1111/j.1365-246X.2006.032 98.x.

Ormeni R., Öztürk S., Fundo A., Çelik K., 2017: Spatial and temporal analysis of recent seismicity in different parts of the Vlora-Lushnja-Elbasani-Dibra transversal fault zone, Albania. Austrian J. Earth Sci., 110, 2, doi: 10.17738/ajes.2017.0015.

Pailoplee S., Choowong M., 2014: Earthquake frequency-magnitude distribution and fractal dimension in mainland Southeast Asia. Earth Planets Space, 66, 8, 1-10, doi: 10.1186/1880-5981-66-8.

Pandey M. R., Tandukar, R. P., Avouac J.-P., Lavé J., Massot J. P., 1995: Interseismic strain accumulation on the Himalayan crustal ramp (Nepal). Geophys. Res. Lett., 22, 7, 751-754, doi : 10.1029/94GL02971.

Prakash R., Singh R. K., Srivastava H. N., 2016: Nepal earthquake 25 April 2015: source parameters, precursory pattern and hazard assessment. Geomatics, Nat. Hazards Risk, 7, 6, 1769-1784, doi: 10.1080/19475705.2016.1155504.

Ramesh P., Martha T. R., Kumar K. V., 2018: Regional variation of stress level in the Himalayas after the 25 April 2015 Gorkha earthquake (Nepal) estimated using b-values. J. Geophys. Eng., 15, 3, 921-927, doi: 10.1088/1742-2140/aaa26c.

Roy P. N. S., Mondal S. K., 2009: Fractal nature of earthquake occurrence in northwest Himalayan region. J. Indian Geophys. Union, 13, 2, 63-68.

Roy S., Ghosh U., Hazra S., Kayal J. R., 2011: Fractal dimension and b-value mapping in the Andaman-Sumatra subduction zone. Nat. Hazards, 57, 1, 27-37, doi: 10.1007/s11069-010-9667-6.

Sapkota S. N., Bollinger L., Klinger Y., Tapponnier P., Gaudemer Y., Tiwari D., 2013: Primary surface ruptures of the great Himalayan earthquakes in 1934 and 1255 . Nat. Geosci., 6, 71-76, doi: 10.1038/ngeo1669.

Schorlemmer D., Wiemer S., Wyss M., 2005: Variations in earthquake-size distribution across different stress regimes. Nature, 437, 539-542, doi: 10.1038/nature04094.

Shanker D., Paudyal H., Singh H. N., 2011: Discourse on seismotectonics of Nepal Himalaya and vicinity: Appraisal to earthquake hazard. Geosciences, 1, 1, 1-15, doi: $10.5923 / \mathrm{j}$.geo.20110101.01.

Shcherbakov R., Turcotte D. L., Rundle J. B., 2015: Complexity and Earthquakes. In: Schubert G. (Ed.): Treatise on Geophysics: Second Edition. Elsevier B.V., 627-653, doi: 10.1016/B978-0-444-53802-4.00094-4.

Shcherbakov R., Turcotte D. L., Rundle J. B., 2004: A generalized Omori's law for earthquake aftershock decay. Geophys. Res. Lett., 31, 11, L11613, doi : 10.1029/2004GL 019808.

Shi Y., Bolt B. A., 1982: The standard error of the magnitude-frequency $b$ value. Bull. Seismol. Soc. Am., 72, 5, 1677-1687, doi: 10.1785/BSSA0720051677.

Singh C., Singh A., Chadha R. K., 2009: Fractal and b-value mapping in eastern Himalaya and southern Tibet. Bull. Seismol. Soc. Am., 99, 6, 3529-3533, doi: 10.1785/0120 090041. 
Smalley R. F., Chatelain J.-L., Turcotte D. L., Prévot R., 1987: A fractal approach to the clustering of earthquakes: Applications to the seismicity of the New Hebrides. Bull. Seismol. Soc. Am., 77, 4, 1368-1381, doi: 10.1785/BSSA0770041368.

Smith W. D., 1981: The $b$-value as an earthquake precursor. Nature, 289, 136-139, doi : 10.1038/289136a0.

Sreejith K. M., Sunil P. S., Agrawal R., Saji A. P., Rajawat A. S., Ramesh D. S., 2018: Audit of stored strain energy and extent of future earthquake rupture in central Himalaya. Sci. Rep., 8, 16697, 1-9, doi: 10.1038/s41598-018-35025-y.

Tiwari R. K., Paudyal H., 2021: Variability of b-value before and after the Gorkha earthquake in the central Himalaya and vicinity. BIBECHANA, 18, 2, 32-42, doi: 10.3126/bibechana.v18i2.31207.

Tosi P., 1998: Seismogenic structure behaviour revealed by spatial clustering of seismicity in the Umbria-Marche Region (Central Italy). Ann. Geophys., 41, 2, 215-224, doi: 10.4401/ag-4331.

Upreti B. N., Kumahara Y., Nakata T., 2007: Paleoseismological study in the Nepal Himalaya - present status. Proceedings of the Korea-Nepal Joint symposium on slope stability and landslides, April 1, 2007, 1-9.

Valerio E., Tizzani P., Carminati E., Doglioni C., 2017: Longer aftershocks duration in extensional tectonic settings. Sci. Rep., 7, 16403, 1-12, doi: 10.1038/s41598-01714550-2.

Wang K., Fialko Y., 2015: Slip model of the 2015 Mw 7.8 Gorkha (Nepal) earthquake from inversions of ALOS-2 and GPS data. Geophys. Res. Lett., 42, 18, 7452-7458, doi: 10.1002/2015GL065201.

Webb A. A. G., Schmitt A. K., He D., Weigand E. L., 2011: Structural and geochronological evidence for the leading edge of the Greater Himalayan Crystalline complex in the central Nepal Himalaya. Earth Planet. Sci. Lett., 304, 3-4, 483-495, doi : 10.1016/j.epsl.2011.02.024.

Wei S., Chen M., Wang X., Graves R., Lindsey E., Wang T., Karakaş Ç., Helmberger D., 2018: The 2015 Gorkha (Nepal) earthquake sequence: I. Source modeling and deterministic 3D ground shaking. Tectonophysics, 722, 447-461, doi : 10.1016/j. tecto. 2017.11 .024$.

Wessel P., Smith W. H. F., Scharroo R., Luis J., Wobbe F., 2013: Generic mapping tools: Improved version released. Eos (Washington DC), 94, 45, 409-410, doi: 10.1002/20 $13 \mathrm{E} 0450001$.

Wiemer S., 2001: A software package to analyze seismicity: ZMAP. Seismol. Res. Lett., 72, 3, 373-382, doi: 10.1785/gssrl.72.3.373.

Wiemer S., Wyss M., 2000: Minimum magnitude of completeness in earthquake catalogs: Examples from Alaska, the Western United States, and Japan. Bull. Seismol. Soc. Am., 90, 4, 859-869, doi: 10.1785/0119990114.

Wu M.-H., Wang J. P., Ku K.-W., 2019: Earthquake, Poisson and Weibull distributions. Physica A, 526, 121001, doi: 10.1016/j.physa.2019.04.237.

$\mathrm{Xu}$ J., 2011: Fractal analysis to study the structural distribution of Wenchuan earthquake in China. Adv. Mat. Res., 243-249, 4097-4100, doi: 10.4028/www.scientific. net/AMR. 243-249.4097. 
Yadav R. B. S., Bayrak Y., Tripathi J. N., Chopra S., Bayrak E., 2012: Regional variation of the $\omega$-upper bound magnitude of GIII distribution in Hindukush-Pamir Himalaya and the adjacent regions: A perspective on earthquake hazard. Tectonophysics, 544-545, 1-12, doi: 10.1016/j.tecto.2012.03.015.

Yeken T., 2016: Spatial Analysis of b-value Variability in Armutlu Peninsula (NW Turkey). Open Geosci., 8, 548-555, doi: 10.1515/geo-2016-0048.

Yin A., Dubey C. S., Webb A. A. G., Kelty T. K., Grove M., Gehrels G. E., Burgess W. P., 2010: Geologic correlation of the Himalayan orogen and Indian craton: Part 1. Structural geology, U-Pb zircon geochronology, and tectonic evolution of the Shillong Plateau and its neighboring regions in NE India. Geol. Soc. Am. Bull., 122, 3-4, 336-359, doi: 10.1130/B26460.1. 